\title{
Gross Total Resection of a Jugular Foramen Thyroid Medullary Metastasis via a Transjugular Transsigmoid Approach
}

\author{
Ilhan Aydin ${ }^{1}$ Sima Sayyahmelli ${ }^{1}$ Mark Pyle $^{1} \quad$ Mustafa K. Baskaya $^{1}$ \\ ${ }^{1}$ Department of Neurological Surgery, University of Wisconsin \\ Medical School, Madison, Wisconsin, United States \\ Address for correspondence Mustafa K. Baskaya, MD, Department of \\ Neurological Surgery, University of Wisconsin Medical School, K4/834 \\ CSC, 600 Highland Avenue, Madison, WI 53792-0001, United States \\ J Neurol Surg B 2018;79(suppl S5):S424-S425. \\ (e-mail: baskaya@neurosurgery.wisc.edu).
}

\begin{abstract}
Surgical resection of jugular foramen tumors poses a significant challenge to skull base surgeons with the selection of an appropriate surgical approach, a matter of some debate. Jugular foramen metastatic tumors may mimic paragangliomas, and in some selected cases surgical resection is needed. In this video, we demonstrate the microsurgical gross total resection of a jugular foramen tumor via a postauricular trans-jugular trans-sigmoid approach. The patient is a 61-year-old man with a 7-year history of medullary thyroid cancer, who underwent three neck operations and radiation to the neck. He developed lower cranial nerve palsies (IX, X, and XI) with preoperative aspiration deficits, dysphonia, status post phonosurgery for vocal cord paralysis, profound sensorineural hearing loss, and muscle atrophy of the left shoulder. He initially received stereotactic radiation of the jugular foramen tumor at an outside hospital without histopathological diagnosis. Follow-up magnetic resonance images (MRIs) showed progressive enlargement of the tumor over the postradiation year. The decision was made to resect this tumor to enable histopathological diagnosis, and to provide local tumor control, since his primary disease has been stable. He

\section{Keywords}

- skull base

- jugular foramen

- thyroid medullary cancer

- metastasis

- transjugular transsigmoid approach underwent microsurgical gross total resection via a transjugular transsigmoid approach. After skeletonizing the sigmoid sinus and jugular bulb, the sigmoid sinus was ligated and rolled toward the jugular bulb, where the major part of the tumor was. Then, using the transjugular route, the tumor was removed en bloc. The surgery and postoperative course were uneventful. The histopathology was a thyroid medullary cancer metastasis. He was followed with serial MRIs, and there was no recurrent tumor at 2 years follow-up. In this video, microsurgical techniques and important steps for the resection of a jugular foramen metastatic tumor are demonstrated.

The link to the video can be found at: https://youtu.be/oXC6fX2CC84.
\end{abstract}

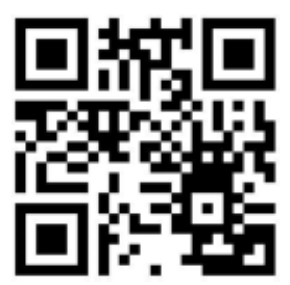

www.thieme.com/skullbasevideos

www.thieme.com/jnlsbvideos

received

May 30, 2018

accepted

August 12, 2018

published online

September 25, 2018
DOI https://doi.org/

10.1055/s-0038-1669970.

ISSN 2193-6331. (c) 2018 Georg Thieme Verlag KG

Stuttgart · New York
License terms

(c) (i) $\ominus \circledast$ 
Conflict of Interest

None.

Disclosure of Funding

None.

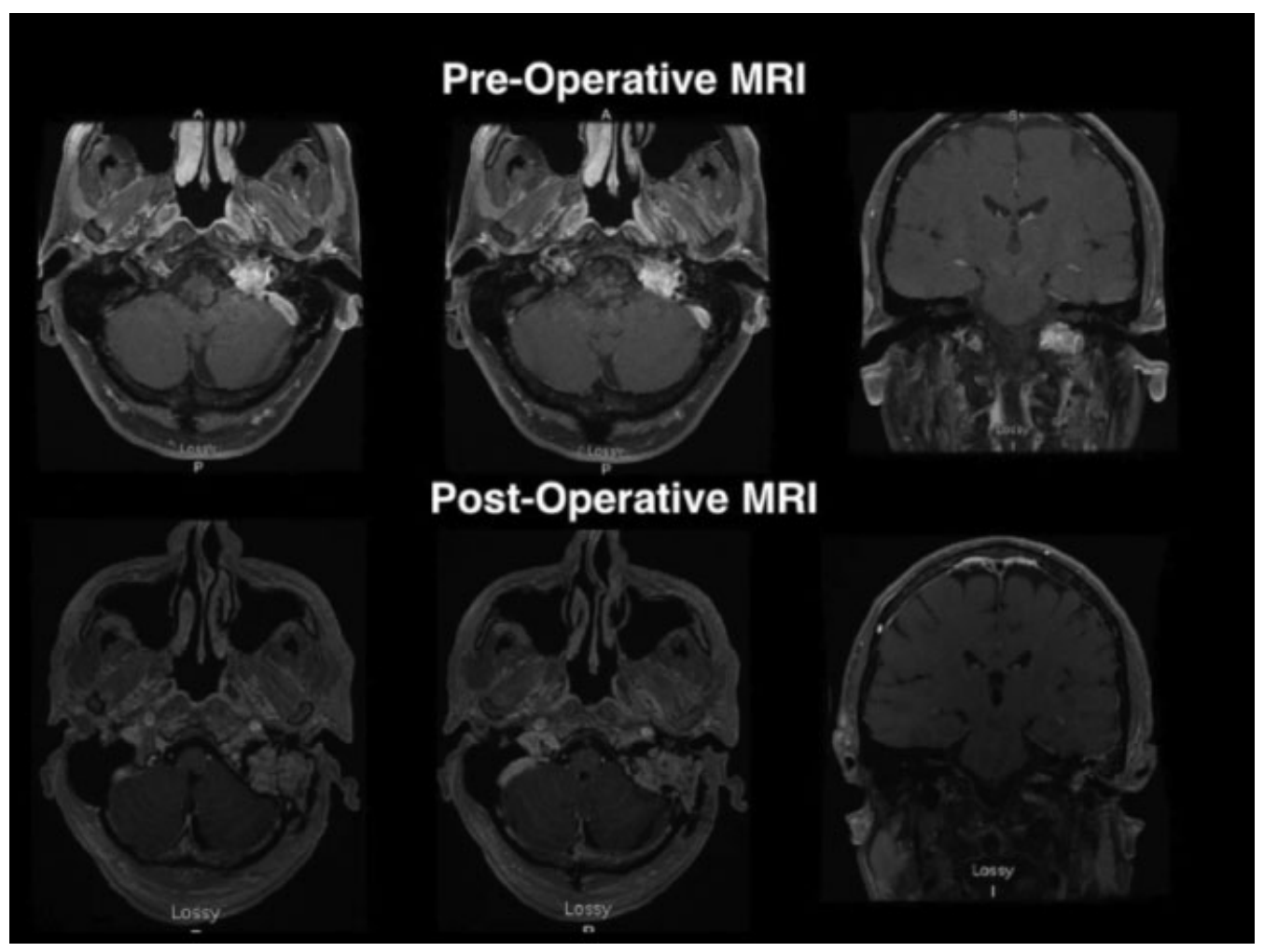

Fig. 1 Pre and postoperative images.

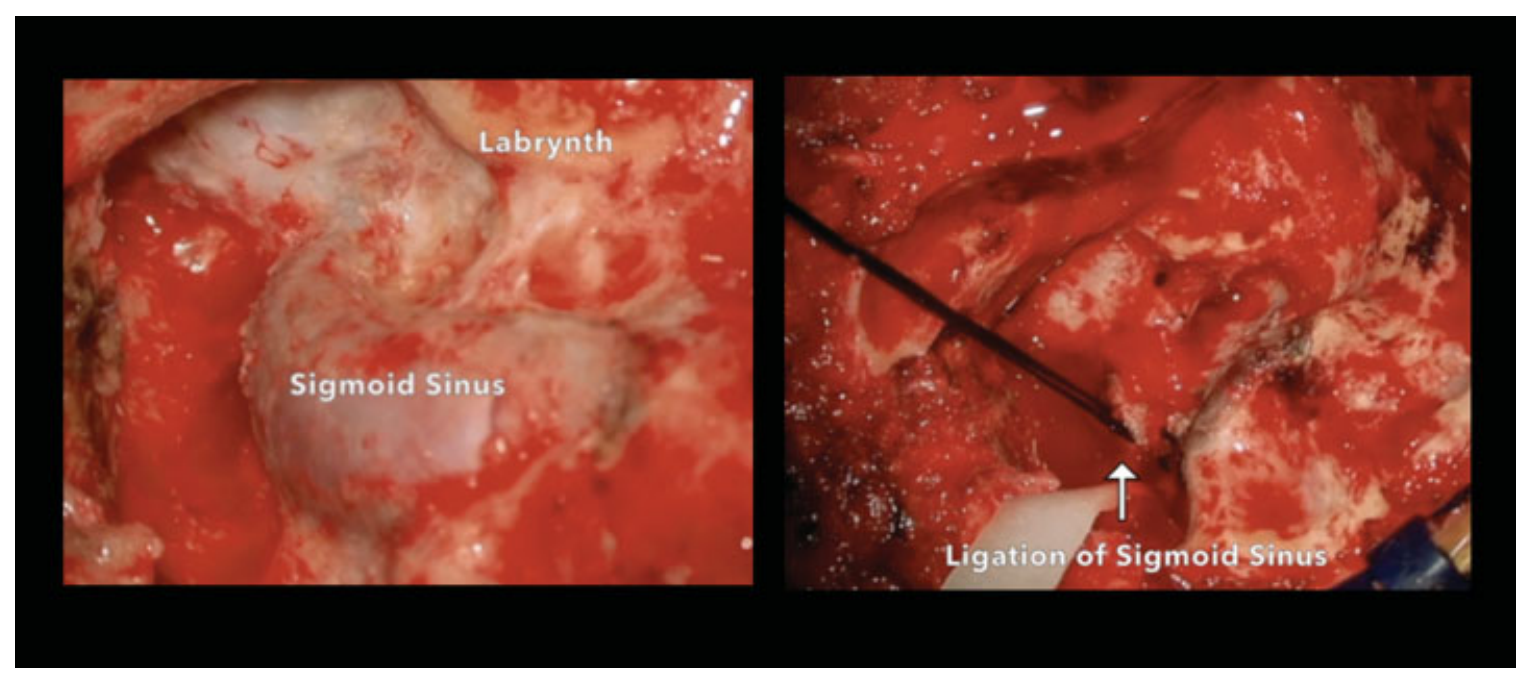

Fig. 2 Intraoperative images. 